\title{
A notificação da violência intrafamiliar contra crianças e adolescentes por profissionais de saúde
}

\author{
Health professionals' reporting of family \\ violence against children and adolescents
}

Hebe Signorini Gonçalves 1

Ana Lúcia Ferreira 1

\footnotetext{
1 Instituto de Puericultura e Pediatria Martagão Gesteira, Universidade Federal do Rio de Janeiro. Av. Brigadeiro Trompowsky $s / n$, Cidade Universitária, Rio de Janeiro, $R J$ 21941-590, Brasil. sigoncal@ism.com.br anaferr@gbl.com.br
}

\begin{abstract}
Reporting family violence against children has two main benefits: it protects the child from the violence and improves epidemiological control of violence. Health professionals play an important role in this area, since they are required to report any known or even suspected case of violence. Nevertheless, when and how to report has been questioned recently. This paper discusses the problems faced by health professionals and suggests specific solutions to the Brazilian case. The authors conclude that it is necessary: (a) to clarify the legal notion of violence in Brazil, specifically the concept of suspicion; (b) to create technical manuals to guide action in this area; (c) to improve the number and quality of services to assist the population; (d) to improve studies and discussion of the consequences of reporting, mainly concerning the notion of justice transmitted to Brazilian families through this practice.
\end{abstract}

Key words Domestic Violence; Adolescent Health Services; Child Health Services

Resumo A notificação é um instrumento duplamente importante no combate à violência: ela produz benefícios para os casos singulares e é instrumento de controle epidemiológico da violência. O profissional de saúde é legalmente obrigado a notificar casos confirmados ou apenas suspeitos de violência e desempenha papel vital nessa área. No entanto, o ato de notificar tem sido objeto de questionamentos por parte desses profissionais. O objetivo deste trabalho é discutir as principais dificuldades enfrentadas pelos profissionais, sugerindo possíveis soluções a serem aplicadas no caso brasileiro. A análise conclui pela necessidade de: (a) esclarecimento da noção legal de maus-tratos e da concepção de suspeita; (b) preparação de manuais técnicos de orientação; (c) melhoria da infra-estrutura de serviços; (d) realização de outros estudos sobre as conseqüências do ato de notificar, especialmente sobre a concepção de justiça que a notificação transmite à família brasileira.

Palavras-chave Violência Doméstica; Serviços de Saúde a Adolescentes; Serviços de Saúde Infantil 


\section{Introdução}

O reconhecimento da ocorrência de maus-tratos contra crianças trouxe como conseqüência direta a necessidade de protegê-las. Tal proteção tem início oficialmente com a notificação da violência à autoridade competente.

No Brasil, os maus-tratos contra a criança só passaram a merecer maior atenção no final dos anos 80. Nessa época, os maus-tratos foram tratados na Constituição Federal (art. 227) (Brasil, 1988) e no Estatuto da Criança e do Adolescente (ECA) (Brasil, 1990), que tornaram obrigatória a notificação de casos suspeitos ou confirmados (art. 13), prevendo penas para os médicos, professores e responsáveis por estabelecimentos de saúde e educação que deixassem de comunicar os casos de seu conhecimento (art. 245). Em 1999, a Secretaria Estadual de Saúde do Rio de Janeiro (SES-RJ, 1999), com a Resolução SES no 1.354, tornou compulsória a notificação de maus-tratos contra crianças e adolescentes até 18 anos incompletos e contra portadores de deficiência, o que indica o reconhecimento da relevância do problema e a disposição de combatê-lo.

A legislação sobre maus-tratos no Brasil tem adotado como parâmetro o modelo americano no que diz respeito à obrigatoriedade de notificar estabelecida para profissionais, à necessidade de encaminhamento da notificação a um organismo designado em lei e à punição para o profissional que não notifica; como nos Estados Unidos, temos realizado várias campanhas enfocando a violência contra a criança. Contamos, no entanto, com uma rede de serviços aquém do necessário, com a escassez de regulamentos que firmem procedimentos técnicos, e com a ausência de mecanismos legais de proteção aos profissionais encarregados de notificar.

Sabe-se que o trabalho na área da violência contra a criança e o adolescente requer intervenção interdisciplinar, e que a ação que visa minorá-la é mais eficaz quando promovida por um conjunto de instituições atuando de modo coordenado. Nesse sentido, a notificação coloca para fora dos limites do serviço de saúde o problema ali detectado e convoca parcerias cuja ação tem-se mostrado imprescindível na área.

A notificação da violência contra a criança inaugura, também, um processo no interior do qual se desenrolam procedimentos de investigação sobre a vida em família, com vistas a subsidiar, se necessário, uma futura decisão jurídica. Para além dos reflexos na vida familiar, a notificação é um poderoso instrumento de política pública, uma vez que ajuda a dimen- sionar a questão da violência em família, a determinar a necessidade de investimentos em núcleos de vigilância e assistência, e ainda permite o desenvolvimento de pesquisas e o conhecimento da dinâmica da violência em família.

Vê-se, assim, que o ato de notificar é um elemento crucial na ação pontual contra a violência, na ação política global e no entendimento do fenômeno. Apesar disso, muita controvérsia permeia ainda o tema, sem perspectivas de solução imediata.

Nossa experiência no Ambulatório da Família (AF) do Instituto de Puericultura e Pediatria Martagão Gesteira (IPPMG), da Universidade Federal do Rio Janeiro (UFRJ) - que em cinco anos de funcionamento atendeu a cerca de 420 crianças e adolescentes vítimas de violência - permite-nos discutir, neste espaço, as principais dificuldades enfrentadas pelos profissionais de saúde na notificação de casos de violência doméstica contra crianças e suas possibilidades de solução.

\section{Entraves à notificação da violência no Brasil}

Apesar das determinações legais contidas no ECA, a subnotificação da violência é uma realidade no Brasil. Isso não surpreende, se considerarmos que o mesmo ocorre em países onde a legislação é mais antiga e os sistemas de atendimento mais aprimorados. Uma pesquisa realizada em trinta países em 1992 mostrou que apenas a metade das nações desenvolvidas e um terço dos países em desenvolvimento dispunham de registros centralizados; em países como Estados Unidos, França e Alemanha, a coleta de dados é fragmentada e com escassa comparabilidade (Daro, 1992, apud Huertas, 1997).

A similaridade parece indicar a presença de dificuldades técnicas específicas do processo de notificar. Aqui também, apesar da obrigatoriedade e do reconhecimento do valor da notificação, os profissionais têm dificuldades em adotá-la como conduta padrão.

Tais dificuldades podem ser resumidamente agrupadas da seguinte forma:

A identificação da violência nos serviços de saúde é ainda carregada de muitas incertezas. A questão não tem sido tratada na maioria dos currículos de graduação (Almeida, 1998) logo, muitos profissionais não dispõem de informações básicas que permitam diagnosticá-la com um mínimo de acurácia.

Ultrapassada a dificuldade inicial em reconhecer os casos, uma outra dúvida tem atra- 
vessado a consciência dos profissionais de saúde: $o$ ato de notificar representa uma quebra do sigilo profissional? O Conselho Regional de Medicina do Estado do Rio de Janeiro (CREMERJ) manifestou-se a esse respeito, em seu Parecer no 76/99 (CREMERJ, 1999). Segundo esse parecer, " a comunicação à autoridade competente não acarreta infração ética por parte do médico, não se configurando, assim, violação do segredo profissional" (CREMERJ, 1999:18), mesmo que se trate apenas de uma suspeita. O Código de Ética dos Psicólogos (CFP, 1987), embora recomende a privacidade e assegure o sigilo (art. 3), prevê que o sigilo seja colocado a serviço do menor impúbere ou interdito, permitindo sua quebra quando se tratar de situações que impliquem conseqüências graves para o próprio atendido ou para terceiros (art. 26 e 27).

Os profissionais brasileiros, à semelhança dos americanos (Gelles, 1997), temem os transtornos legais advindos da notificação.

Além das dificuldades dos profissionais, os casos atendidos têm especificidades que podem facilitar ou dificultar o ato de notificar. Assim, as famílias podem desejar ou tentar impedir a notificação, podem fornecer ou negar informações que fundamentem as suspeitas, podem sentir-se ameaçadas ou protegidas pelo ato de notificar.

Finalmente, há questões estruturais que dificultam o ato de notificar ou fazem com que os profissionais minimizem os benefícios gerados pela notificação. Apesar de os Conselhos Tutelares serem os órgãos designados pelo ECA para receber as comunicações de casos suspeitos ou confirmados de maus-tratos, não estão implementados em todos os municípios brasileiros, e mesmo onde instalados funcionam muitas vezes em condições adversas: trabalhos recentes atestam a falta de infra-estrutura para seu funcionamento, a precariedade de serviços de retaguarda para executar as medidas aplicadas, a formação heterogênea dos conselheiros e a grande demanda de serviços que estes órgãos enfrentam (Camurça, s.d.; Fundação Centro de Defesa dos Direitos Humanos Bento Rubião, 1999).

Como resultado, vê-se que no Brasil a decisão de notificar não se prende à orientação geral da legislação mas sim às peculiaridades de cada caso, e é influenciada por fatores de ordem pessoal dos profissionais, pelas especificidades do caso atendido e pelas próprias estruturas dos serviços, na sua maioria insuficientes.

\section{Superando dificuldades: a experiência do Ambulatório da Família}

A experiência junto às crianças que passaram pelo serviço nestes cinco anos não eliminou dificuldades, mas permitiu que elas fossem enfrentadas com menor desgaste. Tais dificuldades, e as formas para contorná-las, são discutidas a seguir.

O primeiro aspecto a ser considerado é o que diz respeito à suspeita de maus-tratos. $\mathrm{O}$ grau de suspeita varia desde um leve indício de que possa ter havido violência até o relato explícito da criança ou do adulto que a acompanha. Não há como dispensar o mesmo tratamento a situações tão díspares. Uma suspeita leve - eventualmente uma desconfiança que se origina em alterações clínicas ou do comportamento da criança - pode ser melhor investigada no interior de uma relação já construída entre o cliente e o profissional de saúde que faz seu acompanhamento rotineiro. Em tais situações, consideramos viável e útil, para a criança, para a família e para as instituições envolvidas, fundamentar melhor a suspeita antes de encaminhar a notificação.

Casos confirmados de menor gravidade também suscitam dúvidas quanto ao melhor momento para proceder à notificação; nessas situações, o AF adota conduta já recomendada na literatura (Wissow, 1990): preparar a família, esclarecendo a obrigatoriedade por parte da unidade de saúde, o teor da notificação, o que ela significa, a quem é dirigida, suas vantagens e seus possíveis desdobramentos. Nessa negociação, a notificação é apresentada à família como veículo de acesso a instituições e serviços dos quais ela necessita para minorar os efeitos de fatores que alimentam ou favorecem a eclosão da violência. A discussão junto à família e à criança atende a um preceito ético e tem por efeito minimizar os impactos da notificação, observados na nossa prática diária (Ferreira et al., 1999) e confirmados na literatura (Wissow, 1990).

Cabe ressaltar que nenhuma dúvida deve impedir a notificação imediata dos casos de maior gravidade, sejam eles suspeitos ou confirmados, que implicam grave risco para a criança.

Outra fonte de dificuldades é a cultura familiar. Na sociedade brasileira, tende-se a valorizar a privacidade da vida em família, e qualquer intervenção que confronte o discurso dos pais e responsáveis é tida como intrusiva e ofensiva à autoridade paterna. Em tais casos, tentamos mostrar à família que a intenção primeira da notificação é o bem-estar da criança. 
Isto é importante para que a notificação não se transforme em obstáculo capaz de se interpor entre o profissional e os responsáveis, ou entre estes e seus filhos, criando impedimentos para o trabalho de médio e longo prazo, tão necessário quando se trata de transformar os padrões de relacionamento intrafamiliar e reverter formas de interação pautadas pela violência.

Uma outra situação enfrentada no dia a dia do atendimento refere-se àquela em que, embora sejam visíveis os prejuízos causados à criança, a família não se considera violenta, e recusa qualquer forma de intervenção ou auxílio. Esses casos exigem ação de médio e longo prazo, e muitas vezes a medida aplicada pelos Conselhos Tutelares tem sido o próprio acompanhamento realizado no AF (art. 136, $101 \mathrm{e}$ 129 do ECA). Desta forma, os Conselhos são o suporte para o trabalho de conscientizar a família sobre os benefícios gerados por uma alteração nos seus códigos de comunicação.

A ameaça do agressor aos profissionais é um argumento invocado, com certa freqüência, para justificar a não-notificação dos casos de violência. Entre os casos atendidos no AF, esse não tem sido um fator relevante. Maior impacto têm as ameaças dos agressores aos familiares que levaram a violência ao conhecimento do setor saúde; nesses casos, a notificação soma-se a contatos diretos com os conselheiros, que são prevenidos sobre o risco de novas ações violentas na família. Permite-se assim que a intervenção do Conselho seja coordenada com a ação do familiar que buscou o atendimento para a criança e possa proteger a ambos.

A sobrecarga de trabalho e a escassez de infra-estrutura dos Conselhos Tutelares têm sido obstáculos importantes à condução dos nossos casos. O investimento maior do trabalho dos Conselhos se dá sobre os casos de maior gravidade, o que é perfeitamente compreensível, se considerarmos a necessidade de priorizar o investimento humano. Em decorrência, na nossa experiência, o impacto da notificação e da ação dos conselheiros tutelares tem sido pequeno nos casos de menor gravidade e risco.

Temos buscado suprir essa escassez de recursos oferecendo uma assistência mais próxima às famílias com o agendamento de consultas em curto intervalo de tempo, com a convocação por via postal das famílias que por qualquer razão não comparecem às consultas agendadas, e com a realização de visitas domiciliares pelo Serviço Social, quando a família não responde às chamadas. Faltas consecutivas, impossibilidade de localizar as famílias e abandonos de acompanhamento têm sido sistema- ticamente comunicados aos Conselhos, objetivando o retorno ao acompanhamento.

Essa articulação tem sido fonte de soluções, mas eventualmente traz dificuldades. A divergência de condutas entre a unidade de saúde e o Conselho Tutelar a respeito de um caso, ainda que não seja exatamente um entrave à notificação, pode acarretar dúvidas sobre a validade de uma próxima notificação. Mas há que se reconhecer que, ao tratar o tema da violência contra a criança, conceitos e condutas estão ainda em construção, e muitas dúvidas só encontrarão resposta na discussão coletiva entre profissionais e agências de atendimento. Nossa equipe, diante de divergências de conduta, tem discutido caso a caso com os conselheiros.

Do exposto, pode-se deduzir uma linha básica de intervenção adotada pelo AF, diretamente relacionada à decisão de notificar: o instrumento da notificação deve dar início a um processo que se caracteriza muito mais como assistência e auxílio, não como punição. A experiência do AF tem mostrado também que a intervenção do setor saúde pode ser mais efetiva quando a saúde e o bem-estar de todos os envolvidos coloca-se como objeto primeiro da ação, buscando-se equacionar os direitos de todos os membros da família ao invés de alimentar o confronto entre direitos subjetivos.

\section{Considerações finais}

O apelo (legítimo) por fazer cessar a violência não pode ignorar que ela é plural: sua dinâmica e suas manifestações são diversas e, como tal, exigem combate diferenciado. Quando atinge a criança no interior da família, a experiência tem mostrado que punir o responsável não é necessariamente a melhor conduta. Por essa razão, os baixos índices de condenação de pais e responsáveis notificados como violentos não devem ser tomados como indicadores de impunidade ou de ineficácia da notificação.

A legislação brasileira, embora clara quanto à obrigatoriedade de notificar, oferece pouca orientação aos profissionais. Nesse sentido, parece necessário e urgente que:

a) as noções legais sejam esclarecidas, explicitando o que se compreende por maus-tratos e quais as situações que devem ser notificadas;

b) o texto legal se faça acompanhar de discussão a respeito dos diversos manuais de orientação acerca da questão da violência contra a criança existentes no país;

c) a concepção de suspeita seja também esclarecida; na ausência de orientação, notificar uma suspeita fica na prática a cargo da cons- 
ciência individual do profissional, o que pode contribuir tanto para a subnotificação quanto para a supernotificação. Em ambos os casos, compromete-se o bem-estar da criança assim como o dimensionamento epidemiológico da violência;

d) a atuação dos Conselhos Tutelares seja discutida, a fim de melhor capacitar tecnicamente as equipes, disponibilizar recursos para suas

\section{Referências}

ALMEIDA, E. C., 1998. Violência Doméstica: Um Desafio para a Formação do Pediatra. Dissertação de Mestrado, Rio de Janeiro: Instituto de Medicina Social, Universidade do Estado do Rio de Janeiro.

BRASIL, 1988. Constituição da República Federativa do Brasil. Brasília: Senado Federal.

BRASIL, 1990. Lei 8.069/90, de 13 de Julho de 1990. Brasília: Senado Federal.

CAMURÇA, M., s.d. Considerações sobre a Atuação e o Funcionamento dos Conselhos Tutelares no $\mathrm{Mu}$ nicípio do Rio de Janeiro. Rio de Janeiro: Instituto de Estudos de Religião.

CREMERJ (Conselho Regional de Medicina do Estado do Rio de Janeiro), 1999. Parecer no 76/99. Rio de Janeiro: CREMERJ.

CFP (Conselho Federal de Psicologia), 1987. Código de Ética. Resolução CPF no 002/87, de 15 de agosto de 1987. Brasília: CFP.

FERREIRA, A. L.; GONÇALVES, H. S.; MARQUES, M. J. V. \& MORAES, S. R. S., 1999. A prevenção da violência contra a criança na experiência do Ambulatório de Atendimento à Família: Entraves e possibilidades de atuação. Ciência \& Saúde Coletiva, 4:123-130. ações e integrá-las aos demais serviços envolvidos no atendimento às vítimas de violência.

Mas sobretudo, parece necessário discutir as conseqüências do ato de notificar. Aqui, as expectativas dos diversos profissionais e das diversas agências parecem encontrar seu maior desafio. Trata-se de um desafio que fala da concepção de justiça que o ato de notificar e suas conseqüências transmitem às famílias brasileiras.

FUNDAÇÃO CENTRO DE DEFESA DOS DIREITOS HUMANOS BENTO RUBIÃO, 1999. Visualizando a Política de Atendimento à Criança e ao Adolescente - Relatório da Pesquisa. Rio de Janeiro: Litteris Editora.

GELLES, R. J., 1997. Intimate Violence in Families. Thousand Oaks: Sage Publications.

HUERTAS, J. A. D., 1997. Epidemiología. In: Niños Maltratados (J. C. Flores, J. A. D. Huertas \& C. M. González, org.), pp. 15-25, Madrid: Diaz de Santos.

SES-RJ (Secretaria Estadual de Saúde - Rio de Janeiro), 1999. Resolução 1354 de 14 de Julho de 1999. Rio de Janeiro: SES-RJ.

WISSOW, L. L., 1990. Child Advocacy for the Clinician: An Approach to Child Abuse and Neglect. Baltimore: Williams \& Wilkins.

Recebido em 26 de setembro de 2000

Versão final reapresentada em 19 de julho de 2001

Aprovado em 1 de agosto de 2001 